\title{
DEVELOPMENT AND EVALUATION OF MUCOADHESIVE NANOGEL OF NEVIRAPINE FOR VAGINAL APPLICATION
}

\author{
SHEIKH SOFIUR RAHMAN*, ABDUL BAQUEE AHMED \\ *Department of Pharmaceutics, Girijananda Chowdhury Institute of Pharmaceutical Science, Hathkhowapara, Azara, Guwahati, Assam \\ 781017 \\ Email: sofiurgips@gmail.com
}

Received: 05 Feb 2019, Revised and Accepted: 28 Mar 2018

\begin{abstract}
Objective: The main objective of this study was to develop and evaluate Nevirapine nanoparticle loaded mucoadhesive gel (NVP-Np mucoadhesive gel) for vaginal application for the treatment of HIV infection.

Methods: NVP loaded nanoparticles were prepared by salting out method followed by incorporation in different gel bases to produce NVP-Np mucoadhesive gel The prepared gels were evaluated for their physicochemical parameters, rheological characteristics, mucoadhesion, in vitro drug release and ex-vivo permeation of drug across porcine vaginal mucosa.

Results: The result of FT-IR and DSC study confirmed the absence of incompatibility of NVP with excipients used in the formulations. The particle size of the prepared NVP-Np was found to be $243.8 \pm 3.15 \mathrm{~nm}$, a polydispersity index (PI) of $0.787 \pm 0.002$ and zeta potential value- $17.12 \mathrm{mV}$, which revealed the stability of nanoparticles. All the formulations showed good homogeneity, spreadability, physical appearance and content uniformity. The $\mathrm{pH}$ of the mucoadhesive gel formulations was in the range of $3.70 \pm 0.03$ to $4.56 \pm 0.02$, which lies in the normal $\mathrm{pH}$ range of the vaginal fluid. The cumulative amounts permeated at $6 \mathrm{~h}$ were $832.23 \pm 63.45 \mu \mathrm{g} / \mathrm{cm}^{2}, 592.13 \pm 82.55 \mu \mathrm{g} / \mathrm{cm}^{2}$ and $941.32 \pm 81.10 \mu \mathrm{g} / \mathrm{cm}^{2}$ from F1(1\% Chitosan), F2(1\% Carbopol 974P) and F3 (1\% HPMC K100M) respectively. A linear relationship [ $\left.\mathrm{r}^{2}>0.9(0.97 \mathrm{n} 0.99)\right]$ was observed between the percentage cumulative amount permeated and time, indicating zero order kinetics.
\end{abstract}

Conclusion: In conclusion, NVP-Np mucoadhesive gel was prepared successfully using salting out followed by a homogenization technique for vaginal application of NVP for the prophylaxis of HIV infection.

Keywords: Nevirapine, Mucoadhesive gel, HIV infection, Rheological characteristics, Ex-vivo evaluation

(C) 2019 The Authors. Published by Innovare Academic Sciences Pvt Ltd. This is an open-access article under the CC BY license (http://creativecommons.org/licenses/by/4.0/) DOI: http://dx.doi.org/10.22159/ijap.2019v11i3.32353

\section{INTRODUCTION}

Public health, all over the world is facing a serious challenge as occurrences of HIV have become pandemic [1, 2]. A recent report states that 19 million out of 35 million HIV positive people are unaware that they have acquired the virus. Though there are no reports of new HIV infections in the past $10 \mathrm{y}$, still new methodologies for the prevention of HIV infections is the need of the hour [1].

The HIV pandemic has pushed researchers to explore the development of new preventive technologies. Data collected from the developing countries shows that the occurrence of HIV positive is 4 times higher in the case of women aged up to $24 \mathrm{y}$ compared to a man of the same age group. In 2012, there were reports of 2 million new adult infections, especially young African women. Such fig. are mostly seen in developing countries and highlight the vulnerability of women to HIV infections. However, in most countries the use of condoms, (mostly men condom) is the only method to control HIV infection, women cannot insist to use it. Moreover, women who want to conceive cannot use condoms [3].

As revised, elsewhere rings gels films and creams are typical vaginal dosage forms with advantages for particular drugs and particular indications [4]. The development of nanoparticles based vaginal drug delivery mainly focused on pre-exposure prophylaxis. Nanoparticles can provide sustained release of microbicide drugs, which is necessary for maintaining protective drug concentrations between the time of dosing and the time of intercourse. Drug release from nanoparticles can result in more controlled vaginal absorption compared to a drug depot like a vaginal gel, thereby potentially requiring reduced amounts of the drug. Nanoparticles can be designed to contain multiple modalities, to target specific cells, and to have intrinsic antimicrobial activity [4].

NVP, chemically known as 1-cyclopropyl-5,11-dihydro-4-methyl-6Hdipyrido [3,2-b: 2',3'-e] [1, 4] diazepine-6-one is a non-nucleoside reverse transcriptase inhibitor, active against herpes simplex virus type 1 and 2 and against varicella zoster virus1-2. It is a potent nonnucleoside reverse transcriptase inhibitor used in combination with nucleoside analogues for the treatment of HIV infection and AIDS. NVP binds directly to reverse transcriptase and blocks the RNAdependent and DNA-dependent DNA polymerase activities by causing a disruption of the enzyme's catalytic site. The activity of NVP does not compete with template or nucleoside. The most common adverse effect of NVP is the development of mild or moderate rash (13\%) [5].

Mucoadhesive nanogels have gained greater attention as an alternative to conventional gels in the last decade. Mucoadhesive nanogels are easier to handle and administer than conventional gels due to their lesser viscosity in room temperature. On the other hand, the high viscosity of the nanogels at body temperature can minimize chances of gel leakage. Hence developing a mucoadhesive nanogel of NVP may increase the residence time of the formulation and to rapidly penetrate through vaginal mucus in order to deliver the drug to the vaginal epithelium and thereby expected to improve the therapeutic effectiveness of the NVP in the vaginal cavity. Thus, the main objective of this study was to develop and evaluate Nevirapine nanoparticle loaded mucoadhesive gel (NVP-Np mucoadhesive gel) for vaginal application for the treatment of HIV infection.

\section{MATERIALS AND METHODS}

NVP was obtained from Astrix Laboratories Limited (Hyderabad, India) Chitosan was purchased from Sigma-Aldrich (Denmark) Polyvinyl alcohol (PVA), Carbopol 974P, Carboxymethyl cellulose (CMC), HPMC $\mathrm{K} 100 \mathrm{M}$, methylparaben and $\mathrm{MgCl}_{2}$ were purchased from Sigma-Aldrich (Denmark). All chemicals and solvents used in this study were of analytical Grade. HPLC-grade acetonitrile, methanol, potassium phthalate and ammonium acetate were purchased from Sigma (Denmark). Glacial acetic acid (purity 99.8\%) was obtained from Merck (Darmstadt, Germany). Phosphate buffer 
solution ( $\mathrm{pH} 4.5)$ was prepared by mixing appropriate amounts of ammonium acetate and acetic acid.

\section{Drug-excipient compatibility study}

Fourier Transform-Infrared (FT-IR) spectroscopy and Differential Scanning Calorimetry (DSC) was performed to determine the drugexcipient compatibility. FT-IR analysis has been performed using a sample of NVP with various excipients at 1:1 mass/mass ratio used in the formulation. FT-IR spectra were recorded on a Bruker spectrophotometer (Model-220, Germany) in the range of 4000-400 $\mathrm{cm}^{-1}[9,10]$.

A differential scanning calorimeter (Jade DSC, Perkin Elmer, USA) was used for thermal analysis of NVP and NVP-excipients mixtures. Individual samples (NVP and excipients) as well as physical mixtures of NVP and selected excipients (all passed through a 60-mesh sieve) were weighed directly in the pierced DSC aluminium pan and scanned in the temperature range of $20-300{ }^{\circ} \mathrm{C}$ under an atmosphere of dry nitrogen. The heating rate of $10{ }^{\circ} \mathrm{C} / \mathrm{min}$ was used and thermograms obtained were observed for any interaction $[10,11]$.

\section{Fabrication and evaluation of NVP loaded nanoparticles}

NVP-Np were prepared by salting out the method [6]. In brief, 200 $\mathrm{mg}$ of NVP and $30 \mathrm{mg}$ of chitosan were dissolved in $30 \mathrm{ml}$ of acetone at room temperature for $2 \mathrm{~h}$. The organic phase was then incorporated into $70 \mathrm{ml}$ of saturated aqueous solution of polyvinyl alcohol under magnetic stirring to form an $\mathrm{o} / \mathrm{w}$ emulsion. The resulting emulsion was stirred at $1000 \mathrm{rpm}$ for $1 \mathrm{~h}$ and subsequently homogenized at $24,000 \mathrm{rpm}$ for $5 \mathrm{~min}$ using a high-speed homogenizer (IKA T25 digital Ultra Turrax, Germany). To this emulsion, water was added with constant stirring to facilitate diffusion and finally evaporate the organic solvent. This resulted in polymer precipitation and formation of nanoparticles. Free drug and surfactant were separated by centrifugation (REMI cooling centrifuge, Vasai) at 10,000-×g for $20 \mathrm{~min}$.

The particle size and the PI of the prepared nanoparticles were measured immediately by dynamic laser light scattering method at $25^{\circ} \mathrm{C}$ at a scattering angle of $90^{\circ}$ using Zetasizer Nano ZS 90 (Malvern Instruments Ltd. UK). The zeta potential of the preparations was also measured using the clear disposable Zeta cell for zeta potential analysis by electrophoretic mobility method (Zetasizer ZS 90; Malvern Instruments Ltd. UK) [7, 8].

\section{Preparation and evaluation of NVP-Np based mucoadhesive gel}

The prepared NVP-Np was incorporated into three different types of mucoadhesive gel. Each of which contains different types of a mucoadhesive polymer such a Carbopol 974P, Chitosan and HPMC K100M respectively. Weighed quantity $(1 \% \mathrm{w} / \mathrm{w})$ each of Carbopol 974P and HPMC K100M were dispersed separately in water. Chitosan $(1 \% \mathrm{w} / \mathrm{w})$ was dispersed in the glacial acetic acid (GAA) solution. The dispersions were stirred for $2-3 \mathrm{~h}$. NVP-Np (equivalent to $0.2 \% \mathrm{w} / \mathrm{w}$ of NVP) was incorporated into each gel base. Glycerol and methylparaben (MP) were added to the formulations as humectants and preservative respectively with continuous magnetic stirring until a homogeneous dispersion was formed. The dispersion was then neutralized and made viscous by the addition of triethanolamine. The compositions of different mucoadhesive gel formations are listed in (table 1).

Table 1: Formulations composition of NVP-Np based mucoadhesive gel

\begin{tabular}{|c|c|c|c|c|c|c|c|}
\hline F. Code & NVP-Np (\%) & $\begin{array}{l}\text { Chitosan } \\
(\% \mathrm{w} / \mathrm{w})\end{array}$ & $\begin{array}{l}\text { Carbopol 974P } \\
(\% \mathrm{w} / \mathrm{w})\end{array}$ & HPMC K100M (\% w/w) & $\begin{array}{l}\text { Glycerol } \\
\text { (ml) }\end{array}$ & $\begin{array}{l}\text { GAA } \\
(\%)\end{array}$ & $\begin{array}{l}\text { MP } \\
\text { (mg) }\end{array}$ \\
\hline F1 & 0.2 & 1 & -- & -- & -- & 0.5 & 10 \\
\hline F2 & 0.2 & -- & 1 & -- & 15 & -- & 10 \\
\hline F3 & 0.2 & -- & -- & 1 & 0.5 & -- & 10 \\
\hline
\end{tabular}

\section{Evaluation of NVP-Np based mucoadhesive gel}

\section{Physical appearance and spreadability}

The physical appearance and homogeneity of the prepared gels were tested by visual observations [12]. The spreadability of the gel formulations was determined at $24 \mathrm{~h}$ after dissolution, by measuring the spreading diameter of $1 \mathrm{~g}$ of gel between two horizontal plates $(20 \mathrm{~cm} \times 20 \mathrm{~cm})$ after one min. The standardized weight tied on the upper plate was $125 \mathrm{~g}$ [13].

\section{Measurement of $\mathrm{pH}$, drug content and viscosity}

The $\mathrm{pH}$ values of the gel formulations were determined by using a pH meter (Schott CG 840, Germany) at room temperature $24 \mathrm{~h}$ after preparation, and discarding air bubbles. The measurement was performed at 1, 30 and $60 \mathrm{~d}$ after preparation to detect any $\mathrm{pH}$ fluctuation with time [14].

For assay of the drug in gels, NVP was extracted from $1 \mathrm{~g}$ of each gel formulations with $20 \mathrm{ml}$ of methanol for $30 \mathrm{~min}$. The resultant mixture was filtered through a membrane filter (pore size $0.45 \mathrm{~mm}$ ). The absorbance of the sample was determined spectrophotometrically at $230 \mathrm{~nm}$ (Shimadzu UV-1800, Japan) after appropriate dilution with an aqueous solution of phosphate buffer $\mathrm{pH} 4.5$. The concentration of NVP was estimated from the regression equation of the calibration curve.

The viscosity of the gel formulations was determined using Brookfield viscometer (Brookfield DV-III+Rheometer TC-502 Temperature Controller, USA) with spindle no. 64 at 10 r. p. m at the temperature of $30^{\circ} \mathrm{C}$.

\section{Determination of texture profile analysis}

Texture profile analyses of the gels were evaluated using Texture Analyzer (TA. XT. Plus Texture Analyzer, Stable Micro Systems, London, UK) equipped with $5 \mathrm{~kg}$ load cell in texture profile analysis
(TPA) mode. An analytical probe of $1.2 \mathrm{~cm}$ in diameter was depressed twice into each sample to a fixed depth $(15 \mathrm{~mm})$, at a defined rate $(30 \mathrm{~mm} / \mathrm{min})$, with a defined recovery period (15 s), between the end of the first compression and the beginning of the second. A trigger force of $4 \mathrm{~g}$ was applied. At least six replicate analyses of each sample were performed at $37^{\circ} \mathrm{C}$. Data collection and evaluation were done by Texture pro software, version 4.0. Based on the resultant force-time plot, mechanical parameters such as hardness, compressibility, adhesiveness, cohesiveness and elasticity of the gel formulations were determined [15].

\section{Mucoadhesion studies}

The experimental procedure used to determine the mucoadhesion of the different vaginal gel was reported. Mucoadhesion testing of different gels was carried out using a texture analyzer (TA. XT. Plus Texture Analyzer, Stable Micro Systems, London, UK) with a 50N load cell equipped with a mucoadhesive holder. Freshly excised porcine vaginal mucosa was frozen at $-20{ }^{\circ} \mathrm{C}$. A $2 \mathrm{~mm}$ thick section was taken from the inner part of the surface of the frozen vaginal mucosa and attached to the lower end of the probe of the instrument with cyanoacrylate glue. The mucosa was dipped into the phosphate buffer and kept for 10 min prior to the commencement of the experiment. Instrumental parameters (table 2) were used to study the mucoadhesive potential of vaginal gel formulations.

\section{In vitro drug release study}

The in vitro drug release from NVP-Np based mucoadhesive gel was performed across cellulose membranes by using Keshary-Chien diffusion cell [16] with an effective diffusional surface area of 1.54 $\mathrm{cm}^{2}$ and a receptor cell volume of $20 \mathrm{ml}$. The receptor compartment was filled with the solution of phosphate buffer solution $\mathrm{pH} 4.5$ and maintained at $37 \pm 5{ }^{\circ} \mathrm{C}$ with constant magnetic stirring. $1 \mathrm{~g}$ of the gel was placed on the donor compartment and covered with a piece of 
aluminium foil to prevent drying out. The samples $(1 \mathrm{ml})$ were collected from the receptor compartment at the predetermined time interval for $6 \mathrm{~h}$ period and replaced by an equal volume of fresh prewarmed receptor solution to maintain constant volume allowing sink condition throughout the experiment. The amounts of NVP in the samples were determined by HPLC analysis.

Table 2: Testing conditions and instrumental parameters of texture analyzer utilized in the evaluation of the mucoadhesive potential of vaginal gel formulations

\begin{tabular}{ll}
\hline Experimental parameter & Experimental setup \\
\hline Immersion fluid & Phosphate buffer (pH 4.5) \\
Test temperature & 37 \\
Probe speed (mm/s) & 1 \\
Probe force(N) & 0.2 \\
Mucosa contact time(s) & 150 \\
\hline
\end{tabular}

\section{HPLC analysis of NVP}

HPLC analysis of NVP was quantified in samples using high-performance liquid chromatography (HPLC). The HPLC system consisted of a Dual pump (Model M515, Waters Corp., Milford, MA, USA) and UV-Visible detector (Model M2489, Waters Corp., USA) set at a wavelength of 230 $\mathrm{nm}$. The samples were chromatographed on a reverse-phase NOVA-PAK HR C18 column $(4 \mu \mathrm{m}, 150 \times 3.9$ mmd.), (Waters Corp., USA). A mixture of methanol, acetonitrile and buffered solution at $\mathrm{pH} 3.0$ with orthophosphoric acid at 20:20:60 ratios, respectively, was used as the mobile phase. The mobile phase was filtered through a $0.45-\mu \mathrm{m}$ membrane filter and degassed under vacuum and was pumped at a flow rate of $1 \mathrm{ml} / \mathrm{min}$ for the runtime of $10 \mathrm{~min}$, under these experimental conditions $20 \mu \mathrm{l}$ of the sample solution was injected by Rheodyne Injector (Model 7725i, Waters Corp., USA). The column was thermostated at ambient temperature $\left(40^{\circ} \mathrm{C}\right.$ ) (Eunice et al., 2005). The above-mentioned method was validated for specificity, intra-day and inter-day accuracy, precision, and linearity

\section{Ex-vivo permeation study}

This study was carried out using porcine vaginal mucosa because porcine vaginal mucosa seems good in vitro permeability model for human vaginal mucosa [17]. The vaginal tissue was collected from the local slaughterhouse (Azara, Guwahati, India) and was frozen by placing them in containers with a phosphate buffer saline $\mathrm{pH} 4.5$ (PBS) mixtures and stored at-20 ${ }^{\circ} \mathrm{C}$ until use. Prior to the experiment, frozen porcine vaginal tissue specimens were thawed in Krebs solution for $1 \mathrm{~h}$ at $37^{\circ} \mathrm{C}$. Subsequently, the vaginal tissues were dermatomed at a thickness of $300 \pm 50 \mu \mathrm{m}$ and mounted on the Keshary-Chien diffusion cell with an effective diffusional surface area of $1.54 \mathrm{~cm}^{2}$ and a receptor cell volume of $20 \mathrm{ml}$. The receptor compartment was filled with the PBS solution at $37^{\circ} \mathrm{C}$ with constant magnetic stirring. $1 \mathrm{~g}$ of nanogel formulations was placed on the donor compartment and covered with a piece of aluminium foil to prevent drying out. The samples $(1 \mathrm{ml})$ were collected from the receptor compartment at the predetermined time interval for $8 \mathrm{~h}$ period and replaced by an equal volume of fresh prewarmed receptor solution to maintain constant volume allowing sink condition throughout the experiment [18]. The amounts of NVP in the samples were determined by HPLC. Apparent permeability coefficient $\left(\mathrm{P}_{\mathrm{app}}\right)$ values were calculated from permeability data according to the following equation [19].

$$
\mathrm{P}_{\mathrm{app}}=\frac{\mathrm{Q}}{\mathrm{A} \times \mathrm{C} \times \mathrm{t}} \ldots \ldots \ldots \ldots \text { (3) }
$$

Where $\mathrm{Q}$ is the total amount of permeated drug $(\mu \mathrm{g})$, A the diffusion area $\left(\mathrm{cm}^{2}\right), \mathrm{C}$ the initial concentration of drug in the donor compartment $(\mu \mathrm{g} / \mathrm{ml})$ and $t$ the total time of the experiment(s).

\section{Data and statistical analysis}

The steady state flux $\left(J, \mu \mathrm{g} / \mathrm{cm}^{2} / \mathrm{h}\right)$ was calculated from the slope of the linear plot of the cumulative amount permeated per unit area $\left(\mu \mathrm{g} / \mathrm{cm}^{2}\right)$ as a function of time $(\mathrm{t}, \mathrm{h})$. The permeability coefficient $\left(\mathrm{P}_{\text {app }}\right.$, $\mathrm{cm}^{2} / \mathrm{S}$ ) was calculated from the flux and donor drug concentration.

Data are represented as mean $\pm S D(n=3)$. Statistical comparisons were made using Student is

$t$-test at a significance level of $\mathrm{p}<0.05$ using MS Excel software.

\section{Stability study}

For stability study, the F1, F2 and F3 formulations were tightly packed in the aluminium collapsible tube $(5 \mathrm{~g})$ and stored at 25 ${ }^{\circ} \mathrm{C} / 60 \%$ relative humidity (RH) and $40{ }^{\circ} \mathrm{C} / 75 \% \mathrm{RH}$ for a period of 3 mo in a stability chamber (REMI, Environmental Test Chamber, India). Samples were withdrawn in duplicate at 0 and after 1,2 , and $3 \mathrm{mo}$, and their physical and chemical stabilities were inspected. Physical stability was evaluated by visual observation for physical appearance, $\mathrm{pH}$, and rheological properties. Chemical stability was calculated as NVP content, which was determined through HPLC analysis $[20,21]$

\section{RESULTS AND DISCUSSION}

\section{Drug-excipient compatibility study}

FT-IR and DSC carried out an analysis of drug-excipients compatibility study. The FT-IR spectra (fig. 1) of NVP showed characteristics band at $1643.70 \mathrm{~cm}^{-1}$ for $(\mathrm{C}=0$ stretching, aromatic/cyclic amide); $1464.56 \mathrm{~cm}^{-1}(\mathrm{C}=\mathrm{C}$ stretching, aromatic), $1410.03 \mathrm{~cm}^{-1}$ (skeletal vibration stretching), $1288.24 \mathrm{~cm}^{-1}$ (C-N, stretching), $1209.63 \mathrm{~cm}^{-1}$ (C-H in-plane bending), $2950 \mathrm{~cm}^{-1}(\mathrm{~N}-\mathrm{H}$ peak) [22]. These entire characteristics band for NVP were also retained in 1:1 physical mixture of various NVP-excipients mixture (fig. 2). The results indicated the absence of interaction, which was further supported by DSC study [23].

The DSC curve of NVP showed a first endothermic event between 240 and $250^{\circ} \mathrm{C}$ (fig. 3) with a melting temperature of $\left(\mathrm{T}_{\text {onset }}=245.58\right.$ ${ }^{\circ} \mathrm{C}$ ). This endothermic peak was also retained in all the mixture of drug-excipients with a little shifting of the peaks which may be due to the presence of moisture or impurity of the excipient.

\section{Physico-chemical characterization of NVP loaded nanoparticles}

The particle size of the prepared NVP-Np was found to be $243.8 \pm 3.15 \mathrm{~nm}$ with a low PI of $0.787 \pm 0.002$. The low value of PI revealed uniform size distribution of particles. The zeta potential value of NVP-Np was found to be- $17.12 \mathrm{mV}$. The net negative surface charge of the formulations may be due to the use cationic polyelectrolyte (Chitosan) and the addition of polyvinyl alcohol in the formulation aids to reduce aggregation of nanoparticles may indicate the good stability of the formulations [24].

\section{Physico-chemical properties of NVP-Np based mucoadhesive gel}

The results of the physicochemical test of NVP-Np based mucoadhesive gel were shown in (table 3). The results revealed that all the mucoadhesive gel showed good homogeneity, spreadability and physical appearance was observed as white or opaque in nature. The drug content in the gel was found to be $86.93 \pm 5.23$ to $91.23 \pm 6.35 \%$, showing content uniformity. The $\mathrm{pH}$ of the mucoadhesive gel formulations was in the range of $3.70 \pm 0.03$ to $4.56 \pm 0.02$, which lies in the normal $\mathrm{pH}$ range of the vaginal fluid and would not produce any irritation in the vaginal cavity. There was no significant change observed in $\mathrm{pH}$ values (varied from 0.01 to 0.16 ) as a function of time for all formulations. The viscosity of the semisolid dosage form reflects the consistency of the product. The measured value of viscosity was found for F1 (1\% w/w Chitosan), F2 (1\% Carbopol 974P) and F3 (1\% HPMC K100M) as $8123 \mathrm{cps}$, 
8525 cps and 7379 cps respectively. The mucoadhesive gel formulations can be ranked according to their viscosity values as follows: F2 (viscosity 8525 cps) >F1 (viscosity 8123 cps) $>$ F2 (viscosity 7379 cps). Thus, the results of the physicochemical properties suggest the feasibility of the vaginal application of the NVP.

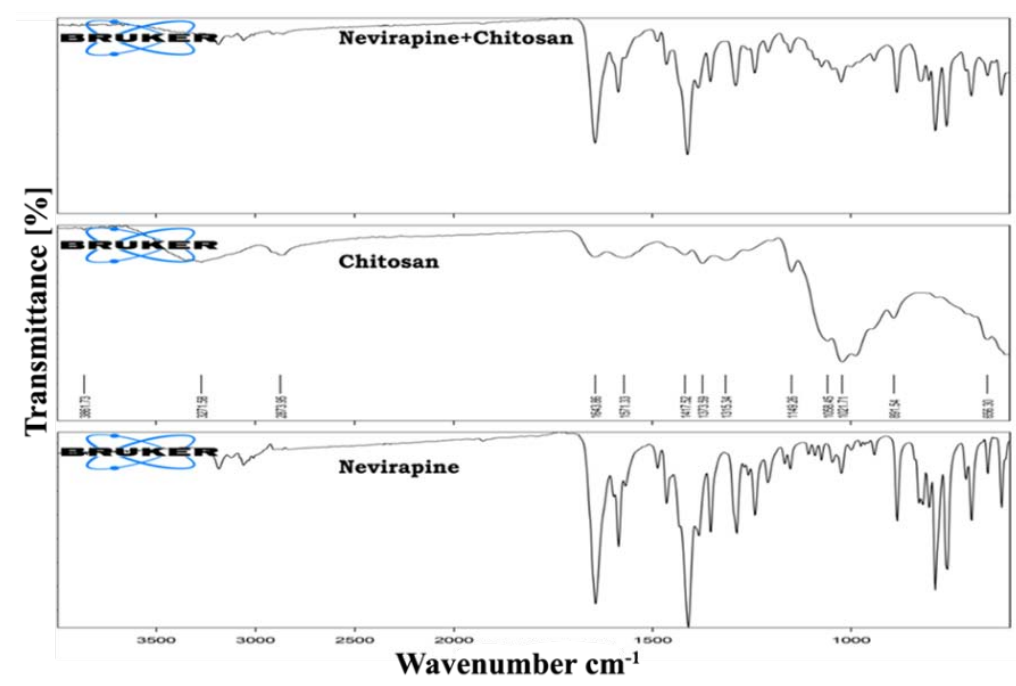

Fig. 1: FT-IR spectra of NVP, chitosan, chitosan+NVP

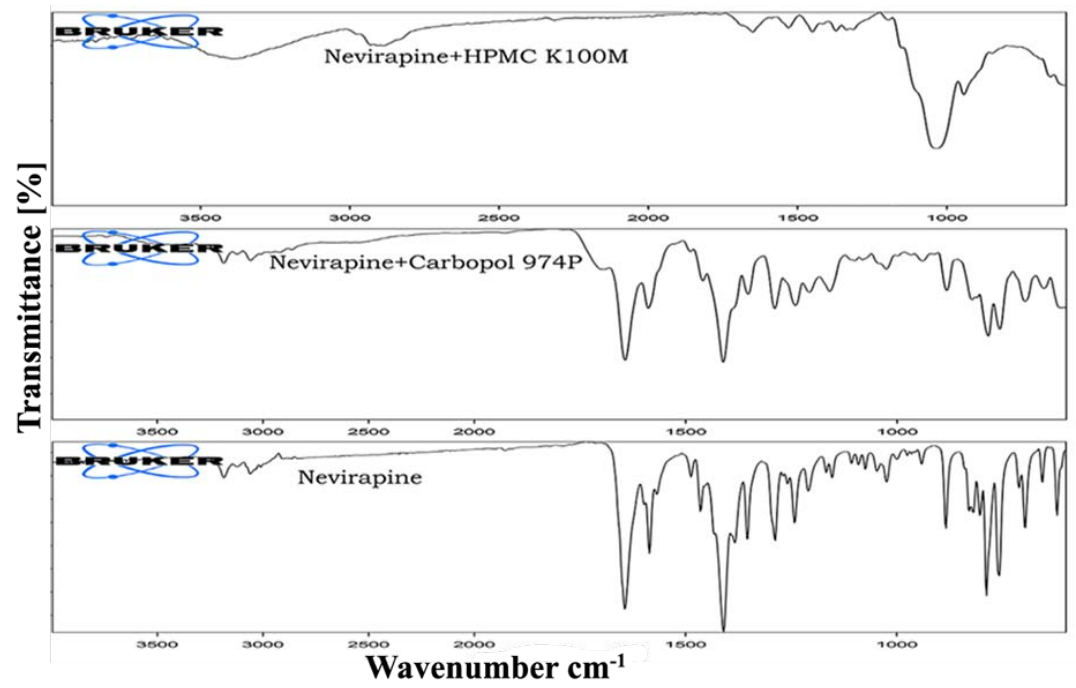

Fig. 2: FT-IR spectra of NVP, NVP+carbopol 974P, NVP+HPMC K100M

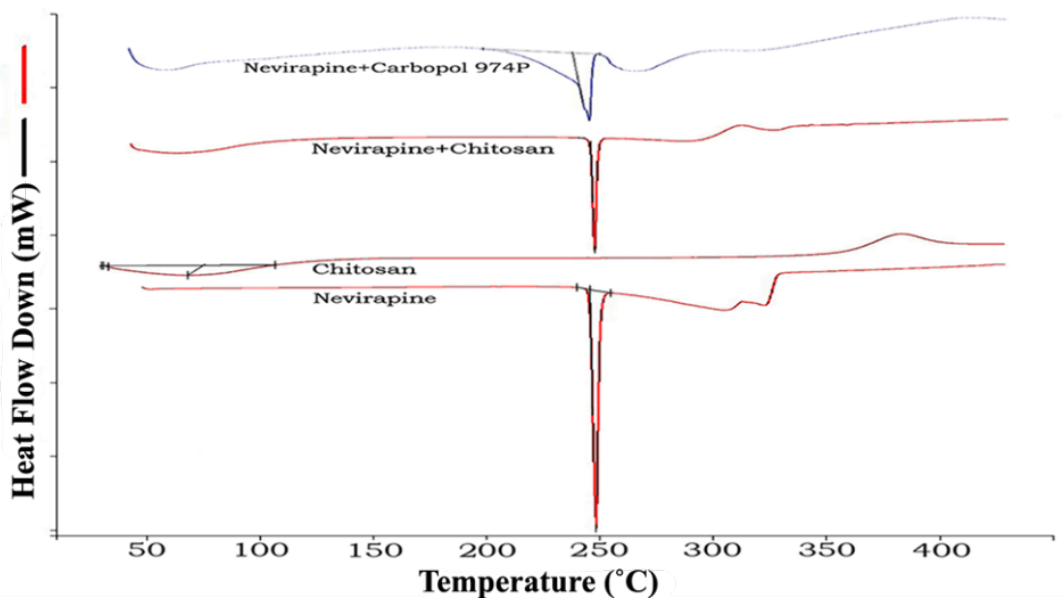

Fig. 3: DSC thermogram of NVP, NVP \pm Chitosan, NVP+Carbopol 974P 
Table 3: Physicochemical evaluation of NVP-Np based mucoadhesive gel

\begin{tabular}{lllll}
\hline F. Code & Spreading diameter after 1 min & \%NVP content & Physical appearance & Homogeneity \\
\hline F1 & 54 & $88.86 \pm 4.22$ & Opaque & Homogeneous \\
F2 & 61 & $86.93 \pm 5.23$ & Opaque & Homogeneous \\
F3 & 49 & $91.23 \pm 6.35$ & White & $4.09 \pm 0.04$ \\
\hline
\end{tabular}

Data presented as mean $\pm S D, n=3$

Table 4: Release parameters of NVP from NVP-Np based mucoadhesive gel across cellulose membrane

\begin{tabular}{|c|c|c|c|c|}
\hline F. Code & Amount release at $6 \mathrm{~h}\left(\mu \mathrm{g} / \mathrm{cm}^{2}\right)$ & Release rate $\left(\mu \mathrm{g} / \mathrm{cm}^{2} / \mathrm{h}\right)$ & The best-fit regression equation for release rate plot & $\mathbf{r}^{2}$ \\
\hline F1 & $987.32 \pm 7.32$ & $164.63 \pm 21.31$ & $12.66 \mathrm{t}-1.4079$ & 0.9924 \\
\hline F2 & $696.34 \pm 8.01$ & $116.08 \pm 26.43$ & $11.298 \mathrm{t}-0.5139$ & 0.9898 \\
\hline F3 & $1042.01 \pm 6.92$ & $173.07 \pm 21.92$ & $13.29 t+3.5543$ & 0.9905 \\
\hline
\end{tabular}

Data presented as mean $\pm S D, n=3$

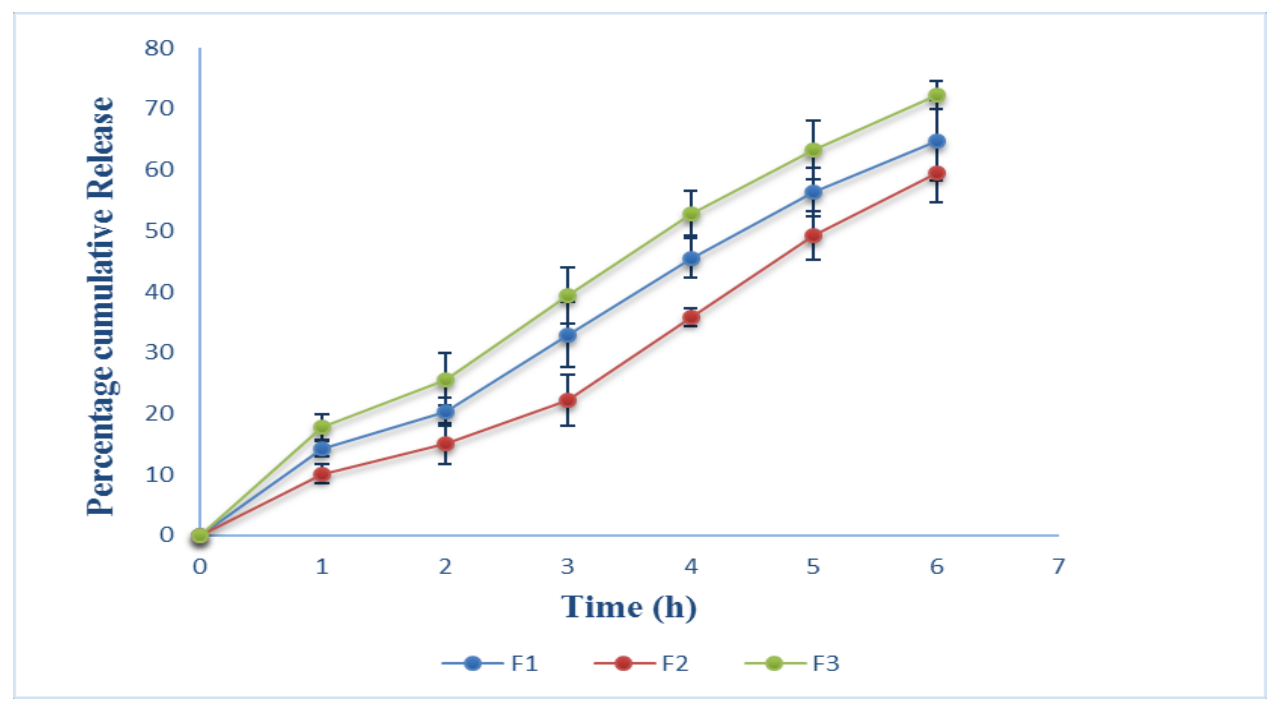

Fig. 4: Comparative permeation profiles of NVP from different NVP-Np based mucoadhesive gel across porcine vaginal mucosa. Data presented as mean $\pm S D(n=3)$

\section{HPLC method validation}

The developed method was showed to be intra-assay and interassay accuracy. The accuracy range was found at $86.70 \%$ to $95.09 \%$ for intra-assay and $96.10 \%$ to $99.10 \%$ for inter-assay respectively. The precision of the method was ascertained by the low value of \% RSD (\% Relative standard deviation) and \% CV (\% Coefficient variation). The value of $\% \mathrm{RSD}$ and $\% \mathrm{CV}$ were found in the range of $0.5 \%-3.15 \%$ and $0.62 \%-3.44 \%$ respectively indicates the precision of the method. The retention time of the NVP was found to be 4.5 min. A linear regression equation of $\mathrm{y}=0.7927 \mathrm{x}-0.0157\left(\mathrm{r}^{2}=\right.$ 0.9998 ) across the full range of concentrations from $30-90 \mu \mathrm{g} / \mathrm{ml}$ was obtained for NVP. The lower limit of quantification was observed as $10 \mu \mathrm{g} / \mathrm{ml}$.

\section{In vitro evaluation}

The experiments for in vitro release of NVP from mucoadhesive gel formulations through cellulose membrane were performed in phosphate buffer solution $\mathrm{pH}$ 4.5. The release parameter is stated in (table 4). It has been observed that the total amount of drug release at $6 \mathrm{~h}$ was found to be $80.62 \%, 70.68$ and $84.94 \%$ for formulations F1, F2 and F3 respectively. The release of the drug was found to be dependent on the nature of the polymer and their consistency. A faster release rate was observed from the gel formulation containing $1 \%$ HPMC K100M (F3) than gel formulation contains 1\% Chitosan (F1) and 1\% Carbopol 974P (F2). At low concentration, HPMC K100M swells quickly and forms a less viscous gel due to the hydrophilic nature and fast hydration. On the other hands, Chitosan
(F1) and Carbopol 974P (F2) gel showed a comparatively slower release rate of the drug due to the formation of a thicker gel which increases the diffusion path length of the drug. Drug release was significantly dependent on polymer type, and release profiles can be ranked in the following order: >HPMCK100M (F3) Chitosan (F1) $>$ Carbopol 974P (F2) and the release of the drug was found to be inversely proportional to the viscosity of the gel formulations. The viscosity for F1, F2 and F3 were found to be $8123 \mathrm{cps}, 8525 \mathrm{cps}$ and 7393 cps. A linear relationship [ $\left.\mathrm{r}^{2}>0.9 \quad(0.98-0.99)\right]$ was obtained between the amount released and the time as proposed by the zero order release theory (10), indicating the diffusion controlled mechanism of drug release.

\section{Mucoadhesion test evaluation}

The present study determines the various mechanical properties as well as mucoadhesive strengths of the gels with the help of Texture Analyser, Stable Micro Systems, London, UK. Results of the texture profile analysis and mucoadhesive strengths are tabulated in (table 5). The hardness of Chitosan gel (F1), Carbopol 974P (F2) and HPMC $\mathrm{K} 100 \mathrm{M}(\mathrm{F} 3)$ was ranged from $13.22 \pm 1.05,19.55 \pm 0.86 \mathrm{~g}$ and $16.26-$ \pm 1.86 g respectively.

Values of adhesiveness of F1, F2 and F3 gels varies from $0.062 \pm 0.003 \mathrm{~g}$ to $0.016 \pm 0.001 \mathrm{~g}$. The cohesiveness of $\mathrm{F} 1$ gels was $0.99 \pm 0.03$. For $F 2$ and $F 3$, it varies from $1.01 \pm 0.04$ to $1.10 \pm 0.03$.

Values of mucoadhesive strengths of the gels are also displayed in (table 5); The mucoadhesive strength for F1, F2 and F3 gels was $16.26 \pm 0.86 \mathrm{~g}, 19.35 \pm 0.85$ and $13.22 \pm 1.05 \mathrm{~g}$ respectively. 
Table 5: Values of texture profile analysis and mucoadhesive strength of conventional gels

\begin{tabular}{lllll}
\hline Formulation code & Hardness(g) & Adhesiveness(g) & Cohesiveness & Mucoadhesive strength(g) \\
\hline F1 & $28.03 \pm 0.32$ & $0.016 \pm 0.001$ & $0.99 \pm 0.03$ & $16.26 \pm 0.85$ \\
F2 & $38.32 \pm 0.65$ & $0.062 \pm 0.003$ & $1.01 \pm 0.04$ & $19.35 \pm 0.86$ \\
F3 & $21.01 \pm 1.13$ & $0.008 \pm 0.002$ & $1.10 \pm 0.03$ & $13.22 \pm 1.05$ \\
\hline
\end{tabular}

Data presented as mean $\pm \operatorname{SD}(n=3)$

\section{Ex vivo permeation evaluation}

The results of ex vivo vaginal permeation of NVP from gels across porcine vagina have been shown in (fig. 4). The vaginal permeation profile showed the same pattern as that of the in vitro release profile across the cellulose membrane. The cumulative amounts permeated at $6 \mathrm{~h}$ were $832.23 \pm 63.45,592.13 \pm 82.55$ and $941.32 \pm 81.10 \mu \mathrm{g} / \mathrm{cm}^{2}$ from the gel formulations containing 1\% Chitosan (F1), 1\% Carbopol 974P (F2), 1\% HPMC K100M (F3) respectively. A linear relationship $\left[r^{2}>0.9(0.97\right.$ n 0.99)] was observed between the cumulative amount permeated and time, indicating zero order kinetics. The apparent permeability coefficient for F1, F2, F3 was found 122.71 \pm 4.1 , $107.63 \pm 2.3$ and $185.43 \pm 6.8 \mathrm{ml} \mathrm{cm}^{-2} \mathrm{~h}^{-1}$ respectively. The highest steady state flux was observed in F3 formulation $(156.63 \pm 10.91$ $\left(\mu \mathrm{g} / \mathrm{cm}^{2} / \mathrm{h}\right)$ and lowest was found in F2 $\left(98.13 \pm 8.31\left(\mu \mathrm{g} / \mathrm{cm}^{2} / \mathrm{h}\right)\right.$ formulation. The flux of different formulations may be compared as F3 $>$ F1 $>$ F2 which suggest an inverse relationship between permeation rate and the viscosity of the gel formulation.

\section{Stability study}

The results of stability studies revealed that the F1, F2, F3 formulations were stable at both the storage conditions in terms of physical and chemical properties. No significant change was observed for physical appearances, $\mathrm{pH}$, and viscosity. The drug content of the formulation before stability and after stability study were found to be $88.86 \pm 4.22 \%, 86.93 \pm 5.23 \%, \quad 91.23 \pm 6.35 \%$ and $87.89 \pm 3.02$, $86.11 \pm 4.34 \%$, $90.93 \pm 1.12 \%$ respectively, revealed no significant chemical change in the formulation after 3 mo of the stability study.

\section{CONCLUSION}

In conclusion, NVP-Np mucoadhesive gel was prepared successfully using salting out followed by homogenization technique. NVP-Np mucoadhesive gel containing $1 \%$ each of Chitosan (F1), Carbopol 974P (F2) and HPMC K100M (F3) showed good physicochemical characteristics with high permeation of NVP across porcine vaginal mucosa. Amongst all the formulations F3 showed better physicochemical characteristics such as viscosity $7393 \mathrm{cps}$, mucoadhesion strength $16.26 \pm 1.86 \mathrm{~g}, \mathrm{pH} 4.56 \pm 0.02$ with good permeation rate $156.63 \pm 10.91 \mu \mathrm{g} / \mathrm{cm}^{2} / \mathrm{h}$ across the porcine vaginal mucosa and followed zero order release kinetics. Hence, F3 formulation may be considered as the best formulation for vaginal application of NVP for the treatment of HIV infection.

\section{AUTHORS CONTRIBUTIONS}

All the author have contributed equally

\section{CONFLICT OF INTERESTS}

Declared none

\section{REFERENCES}

1. Fausi AS, Folkers GK, Dieffenbach CW. HIV-AIDS: much accomplished, much to do. Nat Immunol 2013;14:1104-7.

2. Kallings LO. The first postmodern pandemic: 25 y of HIV/AIDS. J Intern Med 2008;263:218-43.

3. Antimisiaris SG, Mourtas S. Recent advances on anti-HIV vaginal delivery system development. Adv Drug Delivery Rev 2015;92:1-23.

4. Ensign LM, Cone R, Hanes J. Nanoparticle-based drug delivery to the vagina: a review. J Controlled Release 2014;190:500-14.

5. Mallikarjunarao P, Kumar MY, Kumar KM, Prathyusha S, lavanya D. formulation and in vitro evaluation of nevirapine extended release matrix tablets. Int J Res Dev Pharm Lett Sci 2014;3:1054-65.
6. Vyas SP, Khar RK. Targeted and controlled drug delivery novel carrier system. $1^{\text {st }}$ ed. New Delhi: CBS Publishers and Distributors Pvt. Ltd; 2002.

7. Lopez Leon T, Carvalho ELS, Seijo B, Ortega Vinuesa JL, Bastos Gonalez D. Physicochemical characterization of chitosan nanoparticles: electrokinetic and stability behaviour. J Colloid Interface Sci 2005;283:344-6.

8. Tao Z, Timothy FS, Bi-Botti CY. pH-responsive nanoparticles releasing tenofovir intended for the prevention of HIV transmission. Eur J Pharm Biopharm 2011;79:526-36.

9. Ahmed AB, Nath LK. Drug-excipient compatibility studies of nicorandil in controlled release floating tablet. Int J Pharm Pharm Sci 2014;6:468-75.

10. Deshkar S, Sonkamble K, Mahore JG. Formulation and optimization of nanosuspension for improving solubility and dissolution of gemfibrozil. Asian J Pharm Clin Res 2019;12:15763.

11. Tao Z, Timothy FS, Bi-Botti CY. pH-responsive nanoparticles releasing tenofovir intended for the prevention of HIV transmission. Eur J Pharm Biopharm 2011;79:526-36.

12. Ahmed $\mathrm{AB}$, Ahmed $\mathrm{R}$, Sengupta. Formulation and in vitro/exvivo characterizations of microemulsion-based hydrogel formulation of aceclofenac for topical application. Asian J Pharm Clin Res 2016;9(Suppl 1):87-91.

13. Sakharee SS, Yadav AV, Jadhav PD. Design, development and characterization of mucoadhesive gastro spheres of carvedilol. Int J Appl Pharm 2016;8:1-16.

14. Singh G, Rawat N, Singh K, Sarwal A, Sinha VR. Potential of an antidepressant intranasal mucoadhesive microemulsion. Int J Pharm Pharm Sci 2018;10:125-32.

15. Senyigit ZA, Karavana SY, Erac B, Gursel O, Limoncu MH, Baloglu E. Evaluation of chitosan-based vaginal bioadhesive gel formulations for antifungal drugs. Acta Pharm 2014;64:139-56.

16. Keshary PR, Cheien YW. Mechanism of transdermal controlled nitroglycerin administration. Part 2. Assessment of rate controlling steps. Drug Dev Ind Pharm 1984;10:1663.

17. Eyk VAD, Bijl VP. Porcine vaginal mucosa as an in vitro permeability model for human vaginal mucosa. Int J Pharm 2005;305:105-11.

18. Alotaibi FO, Mustafa GM, Ahuja A. Enhanced anti-inflammatory potential of Nigella sativa in topical nanoformulation. Int J Pharm Pharm Sci 2018;10:41-51.

19. Martin Villenaa MJ, Fernandez Campos F, Calpena Campmany AC, Bozal de Febrerc N, Ruiz Martineza MA, Clares Naverosa B. Novel microparticulate systems for the vaginal delivery of nystatin: development and characterization. Carbohydr Polym 2013;94:1-11.

20. Subramanian N, Ghosal SK, Moulik SP. Enhanced in vitro percutaneous absorption and in vivo anti-inflammatory effect of a selective cyclooxygenase inhibitor using microemulsion. Drug Dev Ind Pharm 2005;31:405-16.

21. Barakat NS. Evaluation of glycofurol-based gel as a new vehicle for topical application of naproxen. AAPS Pharm Sci Tech 2010;11:1138-46.

22. Rampino A, Borgogna M, Blasi P, Bellich B, Cesaroa A. Chitosan nanoparticles: preparation, size evolution and stability. Int J Pharm 2013;455:219-28.

23. Jaiswal J, Gupta SK, Kreuter J. Preparation of biodegradable cyclosporine nanoparticles by a high-pressure emulsificationsolvent evaporation process. J Controlled Release 2004;96:169-78.

24. Honary S, Zahir F. Effect of zeta potential on the properties of nano-drug delivery systems-a review (Part 1). Trop J Pharm Res 2013;12:255-64. 